\title{
Design of dualband antenna for RFID applications
}

\author{
N.M. Sahar' ${ }^{1}$, M.T Islam², N.Misran³ \\ ${ }^{1}$ Space Science Centre (ANGKASA), Institute of Climate Change, Universiti Kebangsaan Malaysia, Malaysia \\ ${ }^{2,3}$ Centre of Advanced Electronic and Communication Engineering, Universiti Kebangsaan Malaysia, Malaysia
}

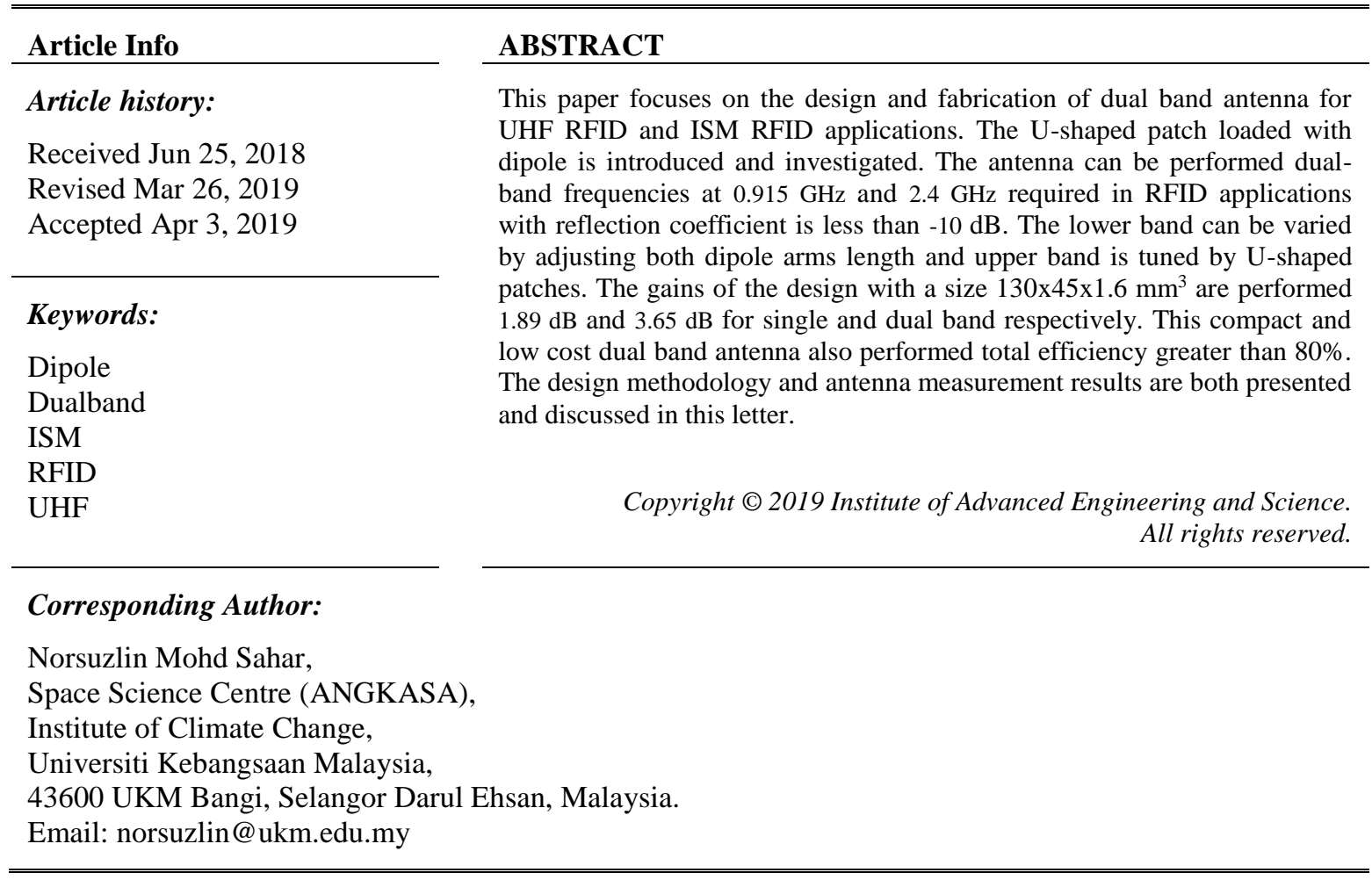

\section{INTRODUCTION}

Multiband Radio Frequency Identification (RFID) antenna has led to great demand in the commercial wireless and service industries. Most of RFID antennas were designed to operate at one or more frequency bands, such as Low Frequency, High Frequency, Ultra High Frequency, and Microwave. Recently, UHF and ISM bands have become more attractive because of their suitability for long-range applications and reconfigurability [1-2]. The dual-band antennas developed conform to various communication protocol standards and established operating frequency bands in one system [3-6]. For that reason, more designs of dual-band antennas for RFID readers were developed to fulfill the requirement of the RFID industry. In [7] a dual band frequency was obtained by controlling the shape and size of the diamond shape patch. The bandwidth was $18 \mathrm{MHz}(902-920 \mathrm{MHz})$ in UHF band and $80 \mathrm{MHz}(2.42-2.5 \mathrm{GHz})$ in ISM band with $150 \mathrm{~mm} \times 127 \mathrm{~mm} \times 5 \mathrm{~mm}$ size antenna. The antenna bandwidth was expanded by utilizing the coupling effect between the notched patch and the resonant aperture for dual-band RFID reader antenna $155 \mathrm{~mm} \times 230 \mathrm{~mm}$ in size [8].

Several methods were approached in designing the multi-frequency antenna from a single frequency antenna [9-14]. In the study by [9] the dual band functionality was achieved though a perturbation method by electrically coupling a two-turn spiral resonator to the antenna. The position of the resonators along the line affects the impedance characteristic. Dual operating frequencies were also achieved by loading two pairs of narrow slots in the triangular patch [11]. By adjusting the slot, protruding a narrow slot out of embedded slots close to the side edges; broad-band radiation was obtained. A triple band was also experimented by placing a cross slot in the ground plane. By embedding a small circular patch into a dual stub loaded on annular ring structure was able to reduce the size by $50 \%$ compared to the conventional annular ring patch and broad impedance bandwidth at $1.17 \mathrm{GHz}, 1.428 \mathrm{GHz}$ and $1.9 \mathrm{GHz}$ was obtained [12]. In [13] dual band antenna 
with high gain was achieved by applying U-shapped feeding strip excites the rectangular ring. In addition, some studies have developed the optimisation performance techniques of RFID antennas regardless of its size such as miniaturized antenna using meander-line [15-17], artificial transmission lines [18] and complementary split ring resonator (CSRR) [19]. Moreover, photo paper with silver nanoparticle conductive ink [20] and biopolymer substrate [21] have been proposed due to flexibility and low cost.

Techniques used to design multi band antenna with dipole configuration were also studied [20-24]. In [22], the dipole was made of two concentric hallow cylinder with different radius anf length. Another method tested is by integrating two patches with the dipoles printed on the same substrate to perform triple band with directional radiation pattern [23]. It consists of a top loaded dipole for lower frequency, two longer dipoles for middle frequency and two shorter dipoles for upper frequency. The antenna was performed in direction patter with antenna gain $7.5 \mathrm{dBi}$ at lowest band, $8.5 \mathrm{dBi}$ at middle band and 9-10 $\mathrm{dBi}$ at highest band. Thus, the integration by two patches was adopted in this study to achieve two frequency bands. The length slot of radiating patch integrated with dipole antenna proposed by [24] able to adjust the desired upper frequency and the bandwidth. By varying the dipole arms for both elements, the lower frequency was obtained.

\section{ANTENNA DESIGN}

In this paper, U-shaped patch loaded with dipole antenna is being proposed. This design will be able to perform dual band antenna inspired by [25]. Li described that the performance of the dipole antenna was not affected by the size condition of Koch fractal. However, the electric dipole's performance is only related to its heights. Thus, the disturbance of dipole height may perform the multiband or wideband antenna. Therefore, the rectangular patch is proposed to be loaded on top of arm length $L_{2}$. The characteristics and the performance of dipole antenna loaded U-shaped patch is studied.

\subsection{U-shaped Patch Antenna Geometry}

The parameters of $L_{1}, W_{1}, L_{2}, L_{3}$ and $W_{2}$ are shown as basic dipole design. For the dual band frequencies, the U-shaped patch structure is loaded with the dipole on the arm length of dipole symmetrically as shown in Figure 1. Analysis is based on the parametric study of parameters $a, b, c, \mathrm{~d}$ and $e$ as U-shaped patch configuration .

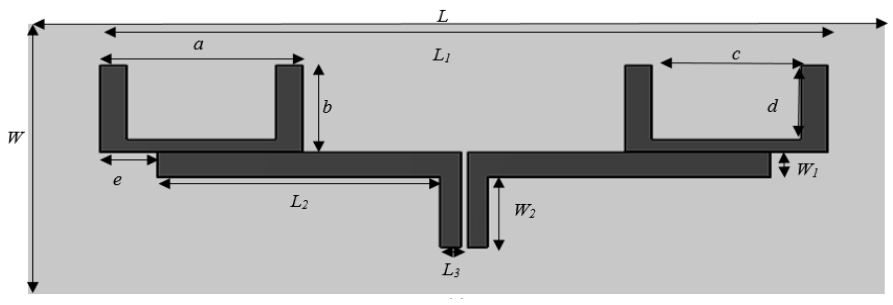

(a)

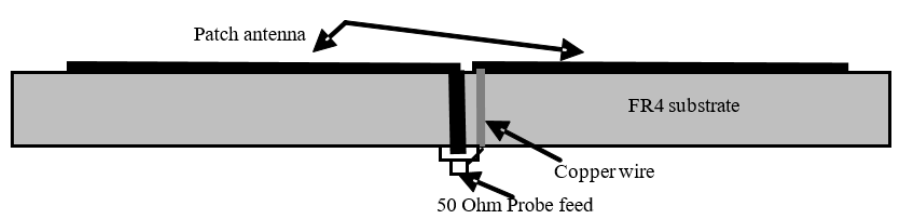

(b)

Figure 1. (a) Geometry of dipole intergrated with U-shaped patch on top view

(b)The structure of FR4 board of proposed antenna on side view

The configuration of dipole is unchanged. Therefore the effects of U-shaped patches is discussed. There are two parts to be investigated which are the effect of loading the rectangular patch without slot and the slot configurations. The reflection coefficient curves results are studied when the parameters are varied. The resonance frequency of dual band performance is compared within $0.915 \mathrm{GHz}$ and $2.4 \mathrm{GHz}$. 


\subsection{Current distribution}

The arm length of the basic dipole is $45 \mathrm{~mm}$ has performed the reflection coefficient with $-22.64 \mathrm{~dB}$ at $1.2275 \mathrm{GHz}$. By integrate the rectangular patch $a \times b \mathrm{~mm}^{2}$ with the basic dipole, dual band is performed. The resonance frequency first band is shifted from $1.2275 \mathrm{GHz}$ which is the reading from basic dipole to $0.915 \mathrm{GHz}$. The reading is decreased because of the length of dipole has increased $\left(L_{2}+e+b\right)$. Consequently, the geometrical path for current resonates is increased. As shown in Figure 2 (a) the lower band of $0.915 \mathrm{GHz}$, the current strongly distributes along the arm dipole geometry.

For upper band at $2.4 \mathrm{GHz}$, it can be observed that the current is intensely travelling around the edge of U-shaped slot of $c \times d \mathrm{~mm}^{2}$. The distance between the feeding point and the rectangular patch has influenced the resonance frequency. The shorter the distance, thus the higher the operating frequency. The slot can be varied the upper band without changes the performance of lower band. This optimized parameter values of RFID application are shown in Table 1.

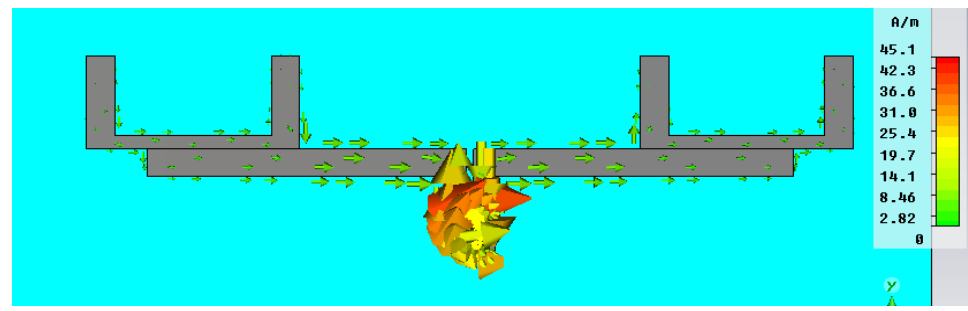

(a)

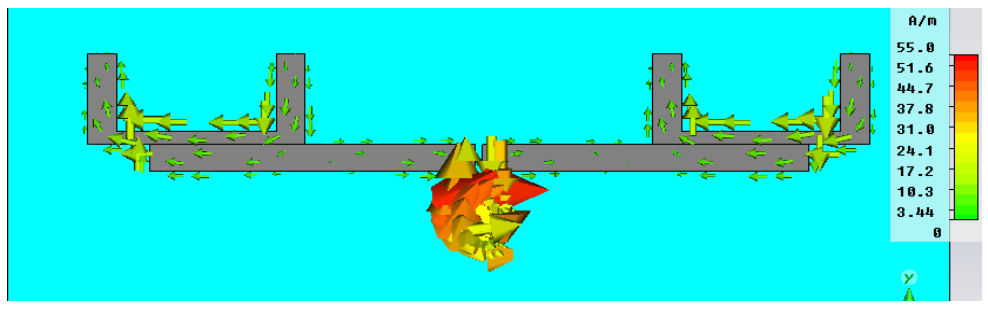

(b)

Figure 2. Current distribution of dipole antenna loaded with U-shaped patches antenna (a) $0.915 \mathrm{GHz}$ at lower band (b) $2.4 \mathrm{GHz}$ at upper band

Table 1.Optimized parameters of the proposed dual band antenna for UHF and ISM RFID applications

\begin{tabular}{cccc}
\hline Parameter & Value $(\mathrm{mm})$ & Parameter & Value $(\mathrm{mm})$ \\
\hline$L$ & 130 & $\mathrm{~W}_{2}$ & 11 \\
$W$ & 45 & $a$ & 30 \\
$L_{1}$ & 108 & $b$ & 13.65 \\
$W_{1}$ & 4 & $c$ & 22 \\
$L_{2}$ & 45.5 & $d$ & 11.65 \\
$L_{3}$ & 3 & $e$ & 8.5 \\
\hline
\end{tabular}

\section{RESULTS AND ANALYSIS}

The optimized parameters of the proposed dual band antenna are shown in Table 1. Antenna prototype of proposed dual-band antenna is performed as depicted in Figure 3 for measuring. Based on the Table 2, the operating frequencies for lower and upper band are same. However, the reflection coefficients of lower band and upper band have shown differently. At lower band, reflection coefficient is excited at 0.9 $\mathrm{GHz}$ with $-25.05 \mathrm{~dB}$ and measured result is $-16.5 \mathrm{~dB}$. For upper band, measured return loss is $-14 \mathrm{~dB}$ as compared the simulated result is $-41.23 \mathrm{~dB}$. The bandwidth is increasing for both resonance frequencies. The lower band is $196 \mathrm{MHz}$ with $8 \%$ increment from the simulated result. In addition, $73 \%$ differences of upper band as compared with the simulated bandwidth at the $87.3 \mathrm{~dB}$ shown in Figure 4 . The gain and directivity at $0.915 \mathrm{GHz}$ are $1.89 \mathrm{dBi}$ and $1.99 \mathrm{~dB}$ respectively. However, the gain and directivity for the upper band is greater than lower band which is $3.65 \mathrm{dBi}$ and $4.37 \mathrm{~dB}$ respectively. At lower band, the efficiency is $97.23 \%$ and $84.72 \%$ at upper band. 
Lastly, the radiation patterns of E-plane and H-plane patterns are discussed as shown in Figure 5 to describe the performance of the antennas. Omnidirectional radiation pattern is performed at $0.915 \mathrm{GHz}$ and $2.4 \mathrm{GHz}$ in H-plane. At lower band, bidirectional in E-plane like a dipole. Besides, the radiation pattern in E-plane is distorted a bit at $2.4 \mathrm{GHz}$ as the current travel around the slot of the U-shaped patches.

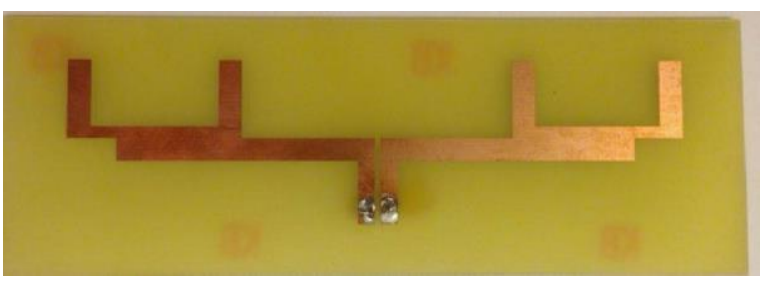

Figure 3. Prototype antenna

Table 2. Comparison result

\begin{tabular}{ccccc}
\hline C-shaped patches loaded & \multicolumn{2}{c}{ Simulated result } & \multicolumn{2}{c}{ Measured Result } \\
with dipole antenna & Lower band & Upper band & Lower band & Upper band \\
\hline Frequency Resonance $(\mathrm{GHz})$ & 0.9 & 2.46 & 0.914 & 2.42 \\
Reflection coefficient $(\mathrm{dB})$ & -25.05 & -41.23 & -16.5 & -14 \\
Bandwidth $(\mathrm{MHz})$ & 109 & 87.3 & 196 & 150 \\
\hline
\end{tabular}

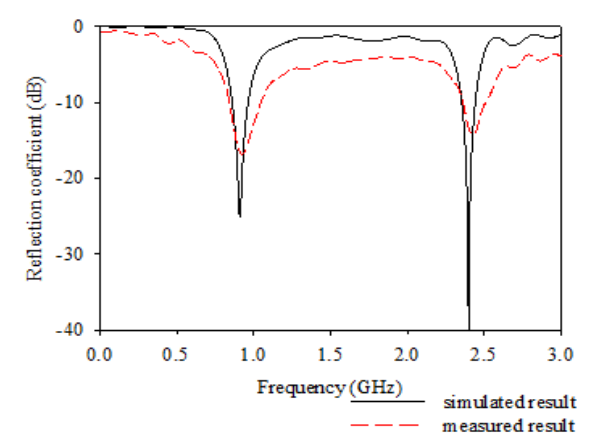

Figure 4. Reflection coefficient curve of proposed antenna

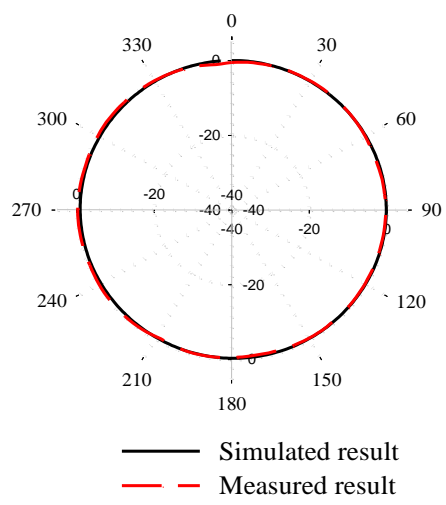

(a)

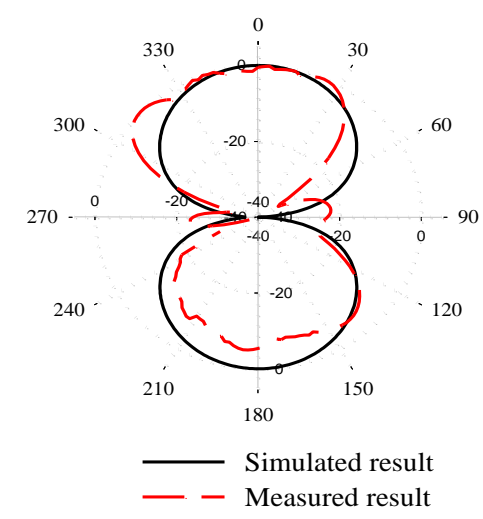

(b)

Figure 5. Radiation patterns of prototype when both switches are $\mathrm{ON}$ (a) $\mathrm{H}$ plane at $0.915 \mathrm{GHz}$

(b) E plane at $0.915 \mathrm{GHz}$ 


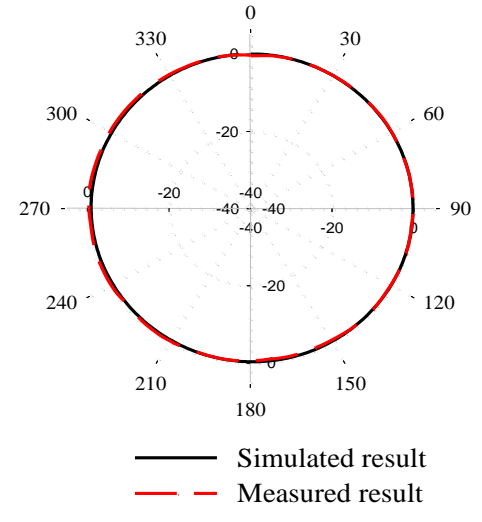

(c)

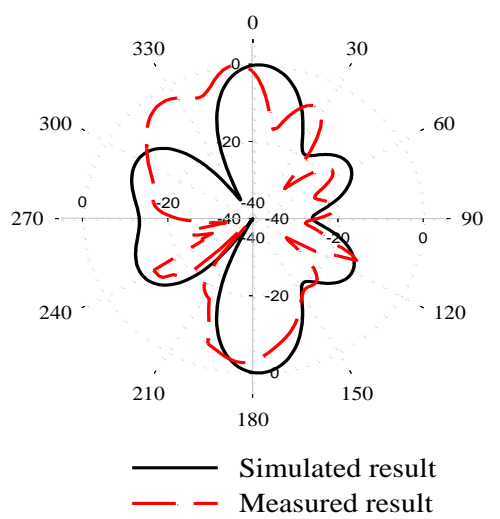

(d)

Figure 5. Radiation patterns of prototype when both switches are $\mathrm{ON}$ (c) $\mathrm{H}$ plane at $2.4 \mathrm{GHz}$ (d) E plane at $2.4 \mathrm{GHz}$

\section{CONCLUSION}

This paper presents the investigation into the basic dipole antenna with the U-shaped patch antenna without a ground plane. Without ground plane, the antenna performance can be improved when RFID integrate with any material [24]. The antenna configuration is initially designed from the basic dipole as planar antenna with coaxial feeding method to achieve low profile and compatibility with printed circuit board. The configuration of U-shaped patches has been placed on the arm length of dipole. It has found that in designing the lower band at $0.915 \mathrm{GHz}$, the parameter of $e$ was affected the arm length which was integrated with the rectangular patch. This was resulted the increment of the geometry of arm length. After the parameters of rectangular of length, $b$ was determined, the slot can be modified to design the upper band. It has been observed that by adjustment of slot length $d$, the upper band was adjusted but the lower band has no changes. Based on the results, the dual band antenna for RFID applications was achieved.

\section{ACKNOWLEDGEMENTS}

The authors would like to thank Universiti Kebangsaan Malaysia (UKM) for partially supporting us in conducting this research through the research grant DPP-2018-004.

\section{REFERENCES}

[1] Raimi Dewan, et al., "Dual Band to Wideband Pentagon-shaped Patch Antenna with Frequency Reconfigurability using EBGs," International Journal of Electrical and Computer Engineering (IJECE), vol.8(4), pp. 2557-2563, 2018 .

[2] N.M. Sahar, et al., "A Reconfigurable Multiband Antenna for RFID and GPS Applications," Elektronika ir Elektrotechnika, vol.21(6), pp. 44-50, 2015.

[3] Zijian Xing, et al., "Dual-Band RFID Antenna for $0.92 \mathrm{GHz}$ Near-Field and $2.45 \mathrm{GHz}$ Far-Field Applications," International Journal of Antennas and Propagation, vol. 2017 Article ID 6803019, 2017.

[4] S. Kibria, et al, "New Compact Dual-Band Circularly Polarized Universal RFID Reader Antenna Using Ramped Convergence Particle Swarm Optimization," IEEE Transactions on Antennas and Propagation, vol. 62, no. 5, pp. 2795-2801, May 2014.

[5] B. Barman, et al., "Dual-Band UHF RFID Tag Antenna Using Two Eccentric Circular Rings," Progress In Electromagnetics Research M, vol. 71, pp. 127-136, 2018.

[6] M.H. Ullah, et al., "Dual Band Printed Quasi-Yagi Antenna for RFID and WLAN Applications," Microwave and Optical Technology Letters, vol.57(11), pp. 2655-2657, 2015.

[7] M.I. Sabran, et al., "A Dual-Band Diamond-Shaped Antenna for RFID Application," IEEE Transactions on Antennas and Propagation, vol.10, pp. 979-982, 2011.

[8] Zishu Xu, et al., "Aperture Coupling Two-layered Dual-band RFID Reader Antenna Design," IEEE International Conference on Microwave and Millimeter Wave Technology, vol. 3, pp. 1218-1221, 2008.

[9] F. Paredes, et al., "Dual-band UHF-RFID Tags Based on Meander-Line Antennas Loaded with Spiral Resonators," IEEE Antennas and Wireless Propagation Letters, vol.10, pp. 768-771, 2011. 
[10] Hemn Younesiraad, et al., "Small MultiBand Rectangular Dielectric Resonator Antennas for Personal Communication Devices," International Journal of Electrical and Computer Engineering (IJECE), vol.4(1), pp. 1-6, 2014.

[11] Lu Jui-Han, et al., "Novel Dual-Frequency and Broad-band Designs of Slot Loaded Equilateral Triangular Microstrip Antennas," IEEE Transactions on Antennas and Propagation, vol.48(7), pp. 1048-1054, 2000.

[12] X.L. Bao, et al., "Compact Concentric Annular-Ring Patch Antenna for Triple-Frequency Operation," Electronics Letters, vol.42(20), pp.1129-1130. 2006.

[13] A.T. Mobashsher, et al., "A Novel High-Gain Dual-Band Antenna for RFID Reader Applications," IEEE Antennas and Wireless Propagation Letters, vol.9, pp. 653-656, 2010.

[14] M. Samsuzzaman, et al., "Compact Lotus Shape Dual Band Patch Antenna for Bluetooth and Ultra Wideband Applications," Microwave and Optical Technology Letters, vol.59(7), pp. 1590-1597, 2017.

[15] Y. Gmih, et al., "A. Fach A Miniature RFID Antenna at UHF Band using Meander-Line Technique," International Journal of Electrical and Computer Engineering (IJECE), vol 8(4), pp. 2280-2289, 2018.

[16] M. Rokunuzzaman et al., "Design of a Miniaturized Meandered Line Antenna for UHF RFID Tags," PLoS ONE vol.11(8): e0161293, 2016.

[17] M.R. Ahsan, et al., "A New Meandered-Stripline Fed Dual Band Patch Antenna," Applied Computational Electromagnetics Society Journal, vol.30(2), pp. 213-221, 2015.

[18] P. Hajizadeh, et al., "Planar Artificial Transmission Lines Loading for Miniturization of RFID Printed Quasi-Yagi Antenna," in IEEE Antennas and Wireless Propagation Letters, vol. 12, pp. 464-467, 2013.

[19] Abdelhadi Ennajih, et al., "A New Dual Band Printed Metamaterial Antenna for RFID Reader Applications," International Journal of Electrical and Computer Engineering (IJECE), vol.7(6), pp.3507-3514, 2017.

[20] M.T. Islam, et al., "Flexible Radio-Frequency Identification (RFID) Tag Antenna for Sensor Applications," Sensors, vol.18(12), pp. 4212, 2018.

[21] M.R. Ahsan, et al., "A New Biopolymer Substrate-based Compact Monopole Antenna covering RFID, WiMAX, and C/X-band," Microwave and Optical Technology Letters, vol.57(9), pp. 2002-2005, 2015.

[22] Tariq Rahim, et al., "Design of Dual Band Sleeve Dipole Antenna for Mobile Jammer Applications," TELKOMNIKA Indonesian Journal of Electrical Engineering, vol.16(1), pp. 1-6, 2015.

[23] R.L. Li, et al., "Directional Triple-band Planar Antenna for WLAN/WiMAX Access Points," Electronics letters, vol.48(62), pp. 305-306, 2012.

[24] M. Hirvonen, et al., "Dual-Band Platform Tolerant Antennas for Radio-Frequency Identification," IEEE Transactions on Antennas and Propagation, vol.54(9), pp. 2632-2637, 2006.

[25] Y. Li, et al., "The analysis and comparison of the electromagnetic radiation characteristic of the Koch fractal dipole antennas," IEEE Conference Antennas Propagation and EM Theory, ISAPE2012, pp.15-18, 2012.

\section{BIOGRAPHIES OF AUTHORS}
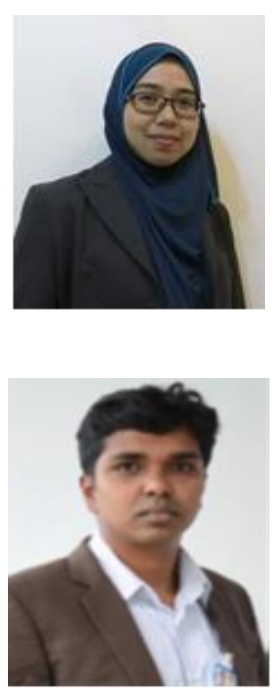

Norsuzlin Mohd Sahar was born in Melaka, Malaysia in 1981. She obtained a BEng degree in Communication Engineering from International Islamic University Malaysia (IIUM) in 2006 and MEng in Universiti Teknologi Malaysia (UTM) in 2010. She received a PhD degree for research in reconfigurable antenna using RF MEMs switches for RFID and GPS applications from the Universiti Kebangsaan Malaysia (UKM) in 2016. She held the lecturing position at USCI University, Kuala Lumpur for several years. She is currently a Lecturer at Electronic \& Electrical Engineering Program, Faculty of Engineering \& the Built Environment, SEGi University, Kota Damansara, Malaysia. Her research interest is in microwave device for wireless applications.

Mohammad Tariqul Islam is a Professor at the Department of Electrical, Electronic and Systems Engineering of the Universiti Kebangsaan Malaysia (UKM) and visiting Professor of Kyushu Institute of Technology, Japan. He is the author of about 350 research journal articles, nearly 165 conference articles, 4 research level books and a few book chapters on various topics related to antennas, microwaves and electromagnetic radiation analysis with 13 inventory patents filed. Thus far, his publications have been cited 3416 times and his H-index is 30 (Source: Scopus). His google scholar citation is 9993 and H-index is 35 . He is now handling many research projects from the Malaysian Ministry of Science, Technology and Innovation and Ministry of Education. His research interests include communication antenna design, radio astronomy antennas, satellite antennas, and electromagnetic radiation analysis. Dr. Islam currently serves as the Editor-in-Chief for the International Journal of Electronics and Informatics and Associate Editor for International Journal of Antenna and Propagation and Electronics Letter. He received several International Gold Medal awards, a Best Invention in Telecommunication Award, a Special Award from Vietnam for his research and innovation, and Best Researcher Awards in 2010 and 2011 at UKM. He also won the best innovation award in 2011 and the Best Research Group in ICT niche in 2014 by UKM. He was the recipient of Publication Award from Malaysian Space Agency in 2014, 2013, 2010, 2009 and the Best Paper Presentation Award in 2012 International Symposium on Antennas and Propagation, 
(ISAP 2012) at Nagoya, Japan and in 2015 in IconSpace. He is a Senior Member of IEEE, Chartered Professional Engineer-CEng, Member of IET (UK) and member of IEICE (Japan).

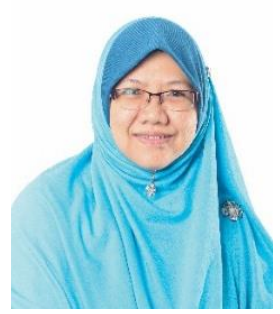

Norbahiah Misran received her BEng in Electrical, Electronic \& System Engineering from Universiti Kebangsaan Malaysia (UKM) in 1999. She completed her Ph.D. degree at the Queen's University of Belfast, Northern Ireland, UK (2004). She started her career as a tutor in 1999 at the Department of Electrical, Electronic \& System Engineering, UKM. She later has been appointed as a lecturer (2004) and an associate professor (2009) at the same department. At present, she is a professor and Chair for Centre of Advanced Electronic and Communication Engineering, Faculty of Engineering and Built Environment, UKM. Her research interest is in microwave device and system particularly in broadband microstrip antennas, reconfigurable antennas and reflectarray antennas. She is also conducting some researches in engineering education field. 